BMC

Public Health

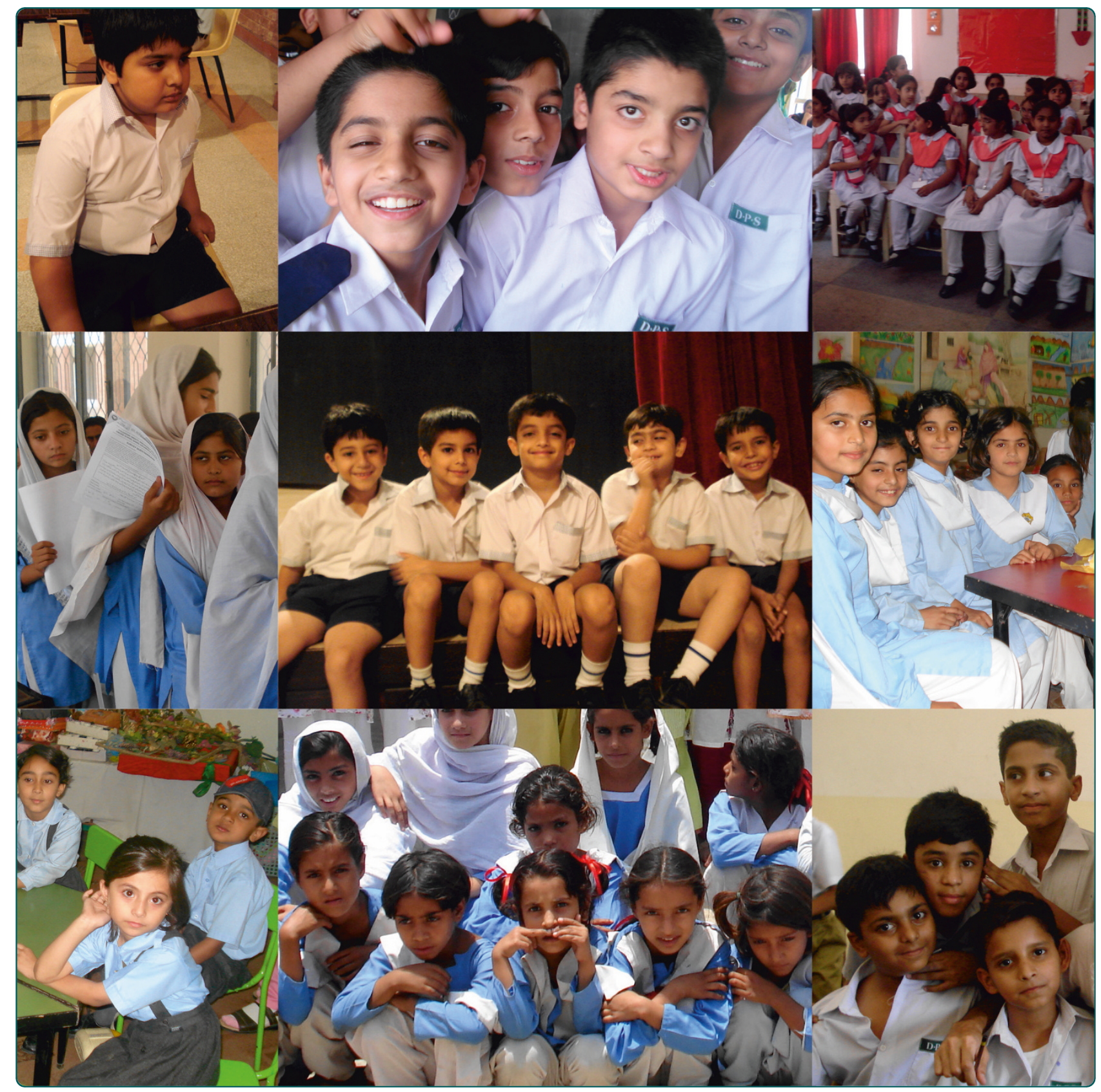

Prevalence and socioeconomic correlates of overweight and obesity among Pakistani primary school children

Mushtaq et al. 


\title{
Prevalence and socioeconomic correlates of overweight and obesity among Pakistani primary school children
}

\author{
Muhammad Umair Mushtaq ${ }^{1,2^{*}}$, Sibgha Gull ${ }^{3}$, Hussain Muhammad Abdullah', Ubeera Shahid', \\ Mushtaq Ahmad Shad ${ }^{2}$ and Javed Akram
}

\begin{abstract}
Background: Childhood obesity is becoming an equally challenging, yet under-recognized, problem in developing countries including Pakistan. Children and adolescents are worst affected with an estimated 10\% of the world's school-going children being overweight and one quarter of these being obese. The study aimed to assess prevalence and socioeconomic correlates of overweight and obesity, and trend in prevalence statistics, among Pakistani primary school children.
\end{abstract}

Methods: A population-based cross-sectional study was conducted with a representative multistage cluster sample of 1860 children aged 5-12 years in Lahore, Pakistan. Overweight ( $>+1$ SD) and obesity (> + 2SD) were defined using the World Health Organization child growth reference 2007. Chi-square test was used as the test of trend. Linear regression was used to examine the predictive power of independent variables in relation to BMI. Logistic regression was used to quantify the independent predictors for overweight and adjusted odds ratios (aOR) with 95\% confidence intervals $(\mathrm{Cl})$ were obtained. All regression analyses were controlled for age and gender and statistical significance was considered at $\mathrm{P}<0.05$.

Results: Seventeen percent (95\% Cl 15.4-18.8) children were overweight and 7.5\% (95\% Cl 6.5-8.7) were obese. Higher prevalence of obesity was observed among boys than girls $(P=0.028)$, however, there was no gender disparity in overweight prevalence. Prevalence of overweight showed a significantly increasing trend with grade ( $P$ $<0.001$ ). Children living in the urban area with high socioeconomic status (SES) were significantly at risk for being overweight and obese (both $P<0.001$ ) as compared to children living in the urban area with lower SES and rural children. Being in higher grade (aOR 2.39, 95\% Cl 1.17-4.90) and living in the urban area with higher SES (aOR 18.10, 95\% Cl 10.24-32.00) independently predicted the risk of being overweight.

Conclusion: Alarmingly rapid rise in overweight and obesity among Pakistani primary school children was observed, especially among the affluent urban population. The findings support the urgent need for National preventive strategy for childhood obesity and targeted interventions tailored to local circumstances with meaningful involvement of communities.

\section{Background}

Overweight and obesity are a global epidemic, with 1 billion overweight people, of whom 300 million are obese, and at least 2.6 million die each year as a result of being overweight or obese [1]. The 2004 World

\footnotetext{
* Correspondence: mushtaqmu@gmail.com

'Ubeera Memorial Research Society, Allama Iqbal Medical College, Lahore, 54000 Punjab, Pakistan

Full list of author information is available at the end of the article
}

Health Assembly at Geneva called for specific action to halt the epidemic that is now penetrating the poorest nations in the world, especially amongst the urban [2,3]. Children and adolescents are worst affected with an estimated $10 \%$ of the world's school-going children being overweight and one quarter of these being obese $[4,5]$. Childhood obesity adversely affects physiological and psychosocial well-being; significantly increases the likelihood for adult obesity; results in non-communicable

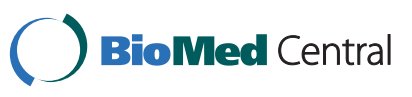


diseases (NCDs) like diabetes, cardiovascular disease and cancer; and leads to increased mortality and morbidity, heavy health expenditures and reduced social status [5-11].

Childhood obesity is becoming an equally challenging, yet under-recognized, problem in the developing countries including Pakistan [10-12]. Targeted interventions, tailored to local circumstances and involving communities, should begin early in life $[13,14]$. Globally, prevalence of childhood overweight and obesity among school-going children has been extensively explored [15-21], and many interventions have been implemented for the prevention of childhood obesity in early school years [22]. In Pakistan, however, it has been neglected and only two surveys with statistically representative sample have been conducted including the National Health Survey of Pakistan (NHSP) 1990-94 and the Karachi survey 2004-05 that reported prevalence of overweight as $3 \%$ and $5.7 \%$ respectively among urban school-aged children [23]. Routine surveillance on prevalence of childhood overweight and obesity has not been conducted in Pakistan, and magnitude of the problem can be determined only through special studies. In 2009-10, a cross-sectional survey titled the Nutritional Assessment among School-going Children in Lahore, Pakistan (NASCL) was conducted among primary school children aged 5-12 years. In Pakistan, it was the third representative sample of nutritional assessment among school-aged children and first large-scale study to explore factors associated with nutritional status. Prevalence and socioeconomic correlates of overweight and obesity, and trend in prevalence statistics, among Pakistani primary school children is the subject of current paper.

\section{Methods}

\section{Design, setting and sample}

This was a population-based cross-sectional study among primary school children aged 5-12 years in Lahore, Pakistan. Lahore is the capital of Pakistan's most populous province Punjab and a metropolis with multiethnic populations. It has a population of about 9 million, including about 2.5 million primary school children aged $5-12$ years, and $81 \%$ of the population resides in the urban area (Administrative data, Government of the Punjab, 2010).

A stratified multistage cluster sample of 1860 children aged 5-12 years in twelve primary schools of City District Lahore was enrolled. The same sampling design has been used previously in nutritional assessment surveys [15-19]. Stratified sampling, based on the population and educational system characteristics, was used to have proportionate representation of gender, area of residence and socioeconomic status (SES). The list of all the public and private primary schools in Lahore was provided by the Punjab Department of Education. The listed schools were stratified according to the geographic area and monthly fee structure of the schools into following four strata: a) urban with high SES (urban area and fee $>2500$ PKR), b) urban with middle SES (urban area and fee $=1000-2500$ PKR), c) urban with low SES (urban area and fee $<1000$ PKR), and d) rural with low/ disadvantaged SES (rural area and fee 100 PKR or free). The former two strata included private (including public-private mix) schools and the later two strata included public schools. In Pakistan, public schools cater low SES urban and rural children while high and middle SES urban children are educated in private and public-private mix schools. Three schools were selected at random from each stratum and contacted by the Departments of Education and Health to participate voluntarily in the study. If the school administration refused to participate, the next school was selected randomly from the respective stratum. For each school, a list of all classes in the five grades (one to five) was obtained and one class in each grade was randomly selected. In this way, 60 classes, five from each school, were selected. For each of the selected classes, first 31 children on the class attendance register, present on data collection day and aged 5-12 years, were included in the study. Children suffering from any known metabolic syndrome (like Prader-Willi syndrome) and children not willing or unable to participate in the study were excluded.

Sample size was calculated using Epi Info 6.04d (US Centers for Disease Control and Prevention, 2004) with a confidence (1- $\alpha$ ) of $95 \%$, anticipated prevalence of $5 \%$, and margin of error of \pm 1 . The minimum sample size calculated was 1823 and a sample of 1860 was deemed sufficient.

\section{Data Collection}

The most frequently used measure for obesity is body mass index (BMI), defined as weight $(\mathrm{kg}) /$ height squared $\left(\mathrm{m}^{2}\right)$, and BMI-for-age is the anthropometric index of relative weight recommended by the international expert committees [24]. For data collection, sampled schools were visited on pre-arranged dates in summer 2009 by teams of trained senior medical students lead by the Principal Investigator. Health education of children and teachers was also carried out after data collection in the respective school.

Analogue physician health scales were used to measure height and weight [25]. All instruments were standardized before the examination and the balances were zero calibrated. Height and weight were measured without shoes and in light summer school uniform. Timing of the measurements was in the mornings or early 
afternoons. Height measurement was in centimeters $(\mathrm{cm})$ and weight was measured in kilogram $(\mathrm{kg})$ with a range of $0-160 \mathrm{~kg}$. Height and weight were measured to the nearest $0.1 \mathrm{~cm}$ and $0.5 \mathrm{~kg}$ respectively. Feet were placed together with heels, buttocks and shoulder blades against the stick and head in the Frankfurt plane with anthropometric square.

For each of the selected classes in the sample, demographic information of all officially enrolled students was obtained before data collection, including gender, date of birth and residential address. Demographic information of students not found on official rosters but currently enrolled in that class was obtained from the classroom teachers. Quality control measures and good practices included training of the surveyors, pre-testing the processes and materials and field monitoring of the data collection. Timely availability of data collection instruments, meeting of survey teams at the end of everyday to share experiences and submission of completed forms and troubleshooting field problems was ensured.

The informed consent statement was printed on the form. Verbal informed consent for the child to participate in the study was taken from class teachers and school heads considering them as guardians. As the study involves no invasive procedure, verbal informed consent was deemed sufficient. The study was approved by the Ethical Review Board of Allama Iqbal Medical College, Lahore. Permissions to conduct the study were granted by the Punjab Departments of Education and Health, and the sampled schools.

\section{Statistical Analysis}

Data was entered and analyzed by manual and computerized checking using SPSS version 18.0 (SPSS Inc. Chicago IL, United States, 2009). Age was calculated to the precise day by subtracting the date of birth from the date of examination. Anthropometric measures including weight, height and BMI were presented with the means and standard deviation (SD). The z-score values for BMI-for-age were calculated by using the World Health Organization's software, AnthroPlus, for assessing growth of the world's children and adolescents (WHO, 2009). Overweight (> + 1SD) and obesity (> + 2SD) were defined using the WHO child growth reference 2007 [26,27]. Prevalence of overweight and obesity was also presented according to the International Obesity Task Force (IOTF) cut-offs [28]. Grade was used in the analyses instead of age for more uniform representation, consistent with previous studies $[15,16]$.

Crude odds ratios (OR) with 95\% confidence intervals (CI) were calculated by univariate analysis to compare prevalence of overweight and obesity among study variables. Bivariate analysis, using chi-square test as the test of trend, was conducted to compare differences in prevalence of overweight and obesity among study variables. Linear regression was used to examine the predictive power of the independent variables (grade and area/SES) in relation to BMI (dependent variable). Logistic regression was used to estimate the simultaneous effect of several determinants on a dichotomous (yes/no) outcome. Grade and area/SES were entered into the multivariate model concurrently to quantify their independent importance for risk of being overweight and adjusted odds ratios (aOR) were obtained. All regression analyses were controlled for age and gender. Statistical significance was considered at $\mathrm{P}<0.05$ and all tests were 2 -sided.

\section{Results}

The study included a sample of 1860 primary school children aged 5-12 years. The male-female ratio was 1.11 with $52.5 \%$ boys and $47.5 \%$ girls. The sample involved $20 \%$ children from each grade and $25 \%$ children from each area and SES stratum. Seventy-five percent children were urban and $25 \%$ children were rural. The median age (range) was eight (5-12) years and the mean age (SD) was 8.49 (1.81) years.

The means (SD) for height, weight and BMI were $128.4(11.4) \mathrm{cm}, 26.9(8.5) \mathrm{kg}$ and $20.7(5.02) \mathrm{kg} / \mathrm{m}^{2}$ respectively [Table 1]. Seventeen percent (95\% CI 15.418.8) children were overweight and 7.5\% (95\% CI 6.58.7 ) were obese. Severe obesity was observed in $2 \%$ (95\% CI, 1.3-2.6) children. According to the IOTF cut-offs, overweight and obesity prevalence was 33\% (95\% CI $31.1-35.3)$ and $24 \%(95 \%$ CI 22.4-26.2) respectively [Table 2].

More boys were overweight (17\%) than girls (16.5\%) but the association was not statistically significant, however, obesity prevalence was significantly higher among boys as compared to girls ( $9 \%$ versus $6 \%, \mathrm{P}=0.028$ ). Prevalence of overweight showed a significantly increasing trend with grade $(\mathrm{P}<0.001)$, with $14.5 \%$ and $11 \%$ overweight children in grades one and two respectively that increased to $17 \%$ overweight children in grade three and to $22 \%$ and $20 \%$ overweight children in grades four and five respectively. Similar trend was noted in the respective age groups. Grade- and gender-specific prevalence of overweight showed a significant positive association with grade among girls $(\mathrm{P}<0.001)$ but the relation was not significant among boys. More boys were overweight in grades one and two while more girls were overweight in grades three to five [Figure 1]. The mean BMI was higher in boys in grades one and two as compared to girls while in grades four and five a higher $\mathrm{BMI}$ in girls was observed than boys [Figure 2].

Children living in the urban area with high SES were significantly at risk for being overweight and obese 
Table 1 Mean and standard deviation (SD) for height, weight and BMI of primary school children in Lahore, Pakistan $(n=1860)$

\begin{tabular}{|c|c|c|c|c|}
\hline Characteristics & $n$ & $\begin{array}{l}\text { Height } \\
\text { (cm) }\end{array}$ & $\begin{array}{l}\text { Weight } \\
\text { (kg) }\end{array}$ & $\begin{array}{l}\text { BMI }(\mathrm{kg} / \\
\left.\mathrm{m}^{2}\right)\end{array}$ \\
\hline \multicolumn{5}{|l|}{ Boys ( $n=977$ ) } \\
\hline 5 years (61-71 months) & 84 & $113.7(7.3)$ & $19.9(4.6)$ & $17.4(3.0)$ \\
\hline 6 years (72-83 months) & 161 & $118.3(5.9)$ & $21.6(5.0)$ & $18.2(3.7)$ \\
\hline 7 years (84-95 months) & 160 & $122.9(8.0)$ & $23.5(5.1)$ & $19.0(3.4)$ \\
\hline $\begin{array}{l}8 \text { years (96-107 } \\
\text { months) }\end{array}$ & 158 & $128.7(7.6)$ & $26.9(5.9)$ & $20.8(3.8)$ \\
\hline $\begin{array}{l}9 \text { years (108-119 } \\
\text { months) }\end{array}$ & 161 & $134.2(8.1)$ & $29.7(7.6)$ & $21.9(4.7)$ \\
\hline $\begin{array}{l}10 \text { years (120-131 } \\
\text { months) }\end{array}$ & 147 & $138.4(8.0)$ & $33.3(9.5)$ & $23.9(5.8)$ \\
\hline $\begin{array}{l}11 \text { years (132-143 } \\
\text { months) }\end{array}$ & 69 & $138.6(7.7)$ & $31.8(6.8)$ & $22.8(4.2)$ \\
\hline $\begin{array}{l}12 \text { years (144-155 } \\
\text { months) }\end{array}$ & 37 & $140.0(8.3)$ & $31.8(7.3)$ & $22.6(4.1)$ \\
\hline \multicolumn{5}{|l|}{ Girls $(n=883)$} \\
\hline 5 years (61-71 months) & 72 & $115.4(7.3)$ & $19.3(3.2)$ & $16.6(2.0)$ \\
\hline 6 years (72-83 months) & 143 & $119.1(7.6)$ & $21.0(4.9)$ & $17.6(3.3)$ \\
\hline 7 years (84-95 months) & 157 & $124.0(6.3)$ & $24.0(5.5)$ & $19.3(3.7)$ \\
\hline $\begin{array}{l}8 \text { years (96-107 } \\
\text { months) }\end{array}$ & 159 & $128.1(7.1)$ & $26.4(6.8)$ & $20.5(4.4)$ \\
\hline $\begin{array}{l}9 \text { years (108-119 } \\
\text { months) }\end{array}$ & 151 & $133.3(7.8)$ & $30.4(8.2)$ & $22.7(5.3)$ \\
\hline $\begin{array}{l}10 \text { years (120-131 } \\
\text { months) }\end{array}$ & 120 & $138.4(9.3)$ & $33.3(10.1)$ & $23.9(6.1)$ \\
\hline $\begin{array}{l}11 \text { years (132-143 } \\
\text { months) }\end{array}$ & 62 & $143.3(9.6)$ & $36.5(11.0)$ & $25.2(6.4)$ \\
\hline $\begin{array}{l}12 \text { years (144-155 } \\
\text { months) }\end{array}$ & 19 & $146.0(9.4)$ & $36.4(9.9)$ & $24.8(5.7)$ \\
\hline
\end{tabular}

(both $\mathrm{P}<0.001$ ) than children living in the urban area with lower SES and rural children. Prevalence of overweight and obesity was $35.5 \%$ and $18 \%$ respectively in the urban children with high SES that decreased to $22 \%$ and $10 \%$ respectively in the urban children with middle SES and to $8 \%$ and $2 \%$ respectively in the urban children with low SES. Only 3\% children living in the rural area (low/disadvantaged SES) were overweight and only $0.6 \%$ children were obese. Overweight and obesity prevalence was $5 \%$ and $1 \%$ respectively in public schools that increased to $29 \%$ and $14 \%$ respectively in private

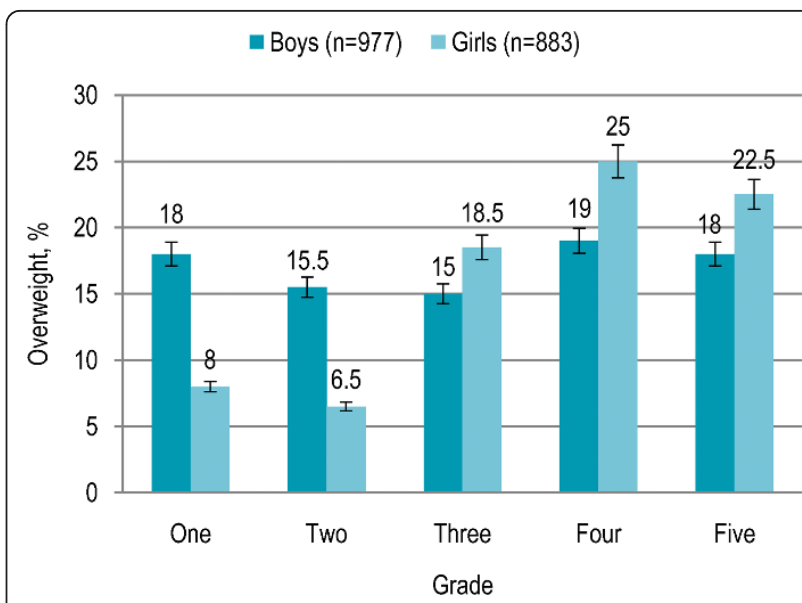

Figure 1 Grade- and gender- specific prevalence (with confidence interval bars) of overweight among primary school children in Lahore, Pakistan $(n=1860)$

(including private-public mix) schools $(\mathrm{P}<0.001)$ [Table 3]. No gender disparity was observed in prevalence of overweight in the rural area and the urban area with middle SES, however, more boys were overweight in the urban area with high SES and more girls were overweight in the urban area with low SES [Figure 3].

In linear regression analysis controlled for age and gender, grade showed a significant positive association with BMI (regression coefficient 0.65, 95\% CI 0.41 to $0.89)$ while area/SES showed a significant inverse association with BMI (regression coefficient -1.54, 95\% CI -1.71 to -1.38 ) [Table 4]. Multiple logistic regression analysis was adjusted simultaneously for age, gender, grade and area/SES. Children in grade four were significantly more likely to be overweight than children in grade one (aOR 2.39, 95\% CI 1.17-4.90) and children living in the urban area with high SES were significantly more likely to be overweight than those living in the rural area with low/disadvantaged SES (aOR 18.10, 95\% CI 10.24-32.00) [Table 5].

In Pakistan, previous studies have reported the prevalence of overweight among urban primary school children aged 5-12 years as 3\% (urban NHSP, 1990-94, $\mathrm{n}=$ 1670 ) and $5 \%$ (Karachi survey, 2004-05, $\mathrm{n}=1381$ ) that

Table 2 Prevalence of overweight and obesity among primary school children in Lahore, Pakistan $(n=1860)$

\begin{tabular}{lllll}
\hline & & & WHO $\mathbf{2 0 0 7}$ & \\
\cline { 5 - 5 } Characteristics & $\mathbf{n}$ & Mean BMI (SD) & \% (95\% Cl) & Mean BMI-for-age z-score (SD) \\
\hline Severely obese & 36 & $33.7(7.1)$ & $1.9(1.3-2.6)^{a}$ & $3.7(0.7)$ \\
Obese & 140 & $31.3(5.7)$ & $7.5(6.3-8.7)^{b}$ & $2.8(0.7)$ \\
Overweight & 316 & $28.5(5.3)$ & $17.0(15.4-18.8)^{c}$ & $2.0(0.8)$ \\
Total sample & 1860 & $20.7(5.0)$ & & $-0.3(1.5)$ \\
\hline
\end{tabular}

${ }^{a}>+3 S D,{ }^{b}>+2 S D,{ }^{c}>+1 S D$ of World Health Organization (WHO) 2007 BMI-for-age reference

d, eInternational Obesity Task Force (IOTF) cut-offs for obesity and overweight respectively 


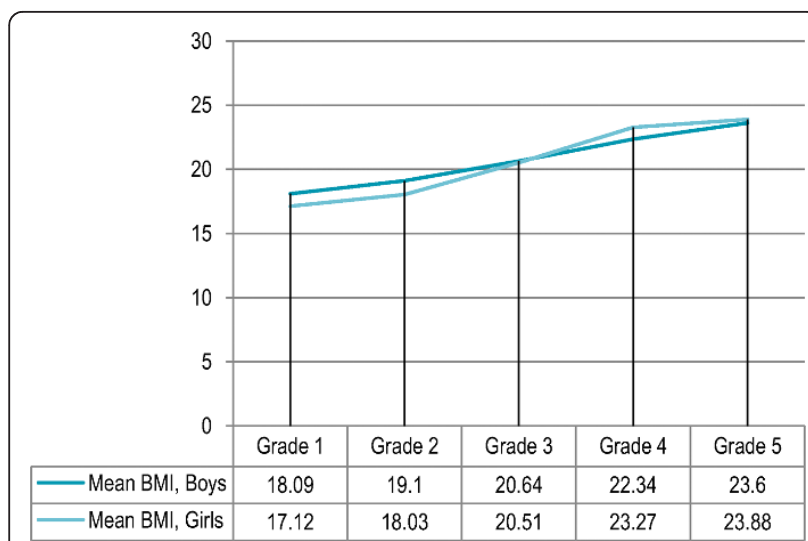

Figure 2 Grade- and gender- specific mean BMI among primary school children in Lahore, Pakistan $(n=1860)$

increased to $19 \%$ in the urban sample of present study (NASCL, 2009-10, $\mathrm{n}=1395$ ) [Figure 4 (a)]. An increasing trend in prevalence of overweight with age was observed in previous studies and it was significantly more pronounced in the present study [Figure 4 (b)].

\section{Discussion}

Prevalence of overweight and obesity among Pakistani primary school children aged 5-12 years was $17 \%$ and $7.5 \%$ respectively. There was four-fold increase in

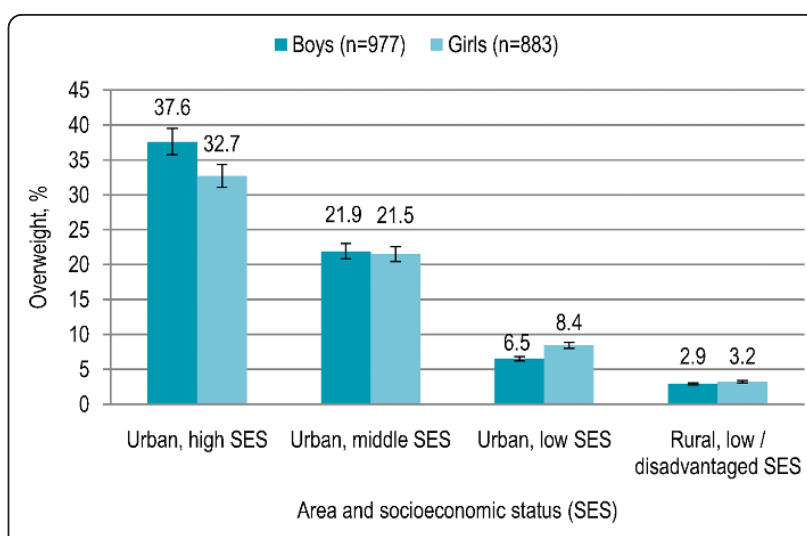

Figure 3 Gender-specific prevalence (with confidence interval bars) of overweight by area and socioeconomic status among primary school children in Lahore, Pakistan $(n=1860)$.

overweight school-aged children in the past five years in the urban Pakistan that highlights the alarmingly rapid rise in childhood overweight and obesity. This pattern is consistent with global trends in childhood obesity observed in the developed countries like United States $[29,30]$. A potential public health issue for the developing countries is the rapidly increasing childhood obesity leading to emerging epidemic of NCDs, which in turn will create an enormous socioeconomic and public health burden in coming decades [9-11,31,32].

Table 3 Sociodemographic factors associated with overweight and obesity in Lahore, Pakistan $(n=1860)$

\begin{tabular}{|c|c|c|c|c|c|}
\hline \multirow[b]{2}{*}{ Characteristics } & \multirow{2}{*}{$\frac{\text { Total Sample }}{\mathrm{n}(\%)}$} & \multicolumn{2}{|c|}{ Over weight $(n=316)$} & \multicolumn{2}{|c|}{ Obese $(n=140)$} \\
\hline & & n (\%) & $P$ value & n (\%) & $P$ value \\
\hline Gender & & & 0.620 & & 0.028 \\
\hline Boys & $977(52.5)$ & $170(17.4)$ & & $86(8.8)$ & \\
\hline Girls & $883(47.5)$ & $146(16.5)$ & & $54(6.1)$ & \\
\hline Grade & & & $<0.001$ & & 0.030 \\
\hline One & $372(20.0)$ & $54(14.5)$ & & $35(9.4)$ & \\
\hline Two & $372(20.0)$ & $41(11.0)$ & & $18(4.8)$ & \\
\hline Three & $372(20.0)$ & $63(16.9)$ & & $26(7.0)$ & \\
\hline Four & $372(20.0)$ & $82(22.0)$ & & $38(10.2)$ & \\
\hline Five & $372(20.0)$ & $76(20.4)$ & & $23(6.2)$ & \\
\hline Age & & & 0.003 & & 0.093 \\
\hline 5-6 years (60-83 months) & $460(24.7)$ & $53(11.5)$ & & $36(7.8)$ & \\
\hline 7-8 years (84-107 months) & $634(34.1)$ & $117(18.5)$ & & $44(6.9)$ & \\
\hline 9-10 years (108-131 months) & $579(31.1)$ & $114(19.7)$ & & $53(9.2)$ & \\
\hline 11-12 years (132-155 months) & $187(10.1)$ & $32(17.1)$ & & $07(3.7)$ & \\
\hline Area and socioeconomic status (SES) & & & $<0.001$ & & $<0.001$ \\
\hline Urban, high SES & $465(25.0)$ & $165(35.5)$ & & $82(17.6)$ & \\
\hline Urban, middle SES & $465(25.0)$ & $101(21.7)$ & & $47(10.1)$ & \\
\hline Urban, low SES & $465(25.0)$ & $36(7.7)$ & & $08(1.7)$ & \\
\hline Rural, low/disadvantaged SES & $465(25.0)$ & $14(3.0)$ & & $03(0.6)$ & \\
\hline School type & & & $<0.001$ & & $<0.001$ \\
\hline Public & $930(50.0)$ & $50(5.4)$ & & $11(1.2)$ & \\
\hline Private (and public-private mix) & $930(50.0)$ & $266(28.6)$ & & $129(13.9)$ & \\
\hline
\end{tabular}


Table 4 Linear regression analysis of factors associated with BMI among primary school children in Lahore, Pakistan (n = 1860) ${ }^{a, b}$

\begin{tabular}{|c|c|c|c|}
\hline Characteristics & $\begin{array}{l}\text { Regression coefficient }(95 \% \\
\mathrm{Cl})\end{array}$ & $\begin{array}{l}\text { Standard } \\
\text { error }\end{array}$ & $\begin{array}{l}\mathrm{P} \\
\text { value }\end{array}$ \\
\hline (Constant) & 15.04 (13.73 to 16.35$)$ & 0.67 & $\begin{array}{l}< \\
0.001\end{array}$ \\
\hline Grade $^{c}$ & 0.65 (0.41 to 0.89 ) & 0.12 & $\begin{array}{l}< \\
0.001\end{array}$ \\
\hline Area and SES ${ }^{d}$ & $-1.54(-1.71$ to -1.38$)$ & 0.08 & $\begin{array}{l}< \\
0.001\end{array}$ \\
\hline
\end{tabular}

${ }^{\mathrm{a}}$ The model is adjusted for age and gender

${ }^{\mathrm{b}} \mathrm{R}^{2}=0.355$

'Grades: 1-5 grades

${ }^{\mathrm{d}}$ Area and socioeconomic status (SES) strata: 1. Urban with high SES, 2. Urban with middle SES, 3. Urban with low SES, and 4. Rural (low/disadvantaged SES)

Worldwide, NCDs account for about $60 \%$ deaths annually and the disease burden is currently greatest and continuing to grow in the developing countries where $66 \%$ of these deaths occur [2].

Prevalence of overweight by the IOTF cut-offs was twice the prevalence by the WHO 2007 reference (33\% versus $17 \%$ ) and prevalence of obesity by the IOTF cutoffs was three times higher than that calculated by the WHO 2007 reference (24\% versus 7.5\%). Using IOTF cut-offs for overweight and obesity in Pakistani schoolaged children would result in higher estimates than the WHO 2007 reference. In Pakistan, present study is the first to report prevalence statistics by the WHO 2007 and IOTF cut-offs.

More boys were overweight than girls but the association was not statistically significant, however, obesity prevalence was significantly higher among boys than girls in line with the results reported in urban India, Brazil, Finland, Canada, and Asian-Americans in United

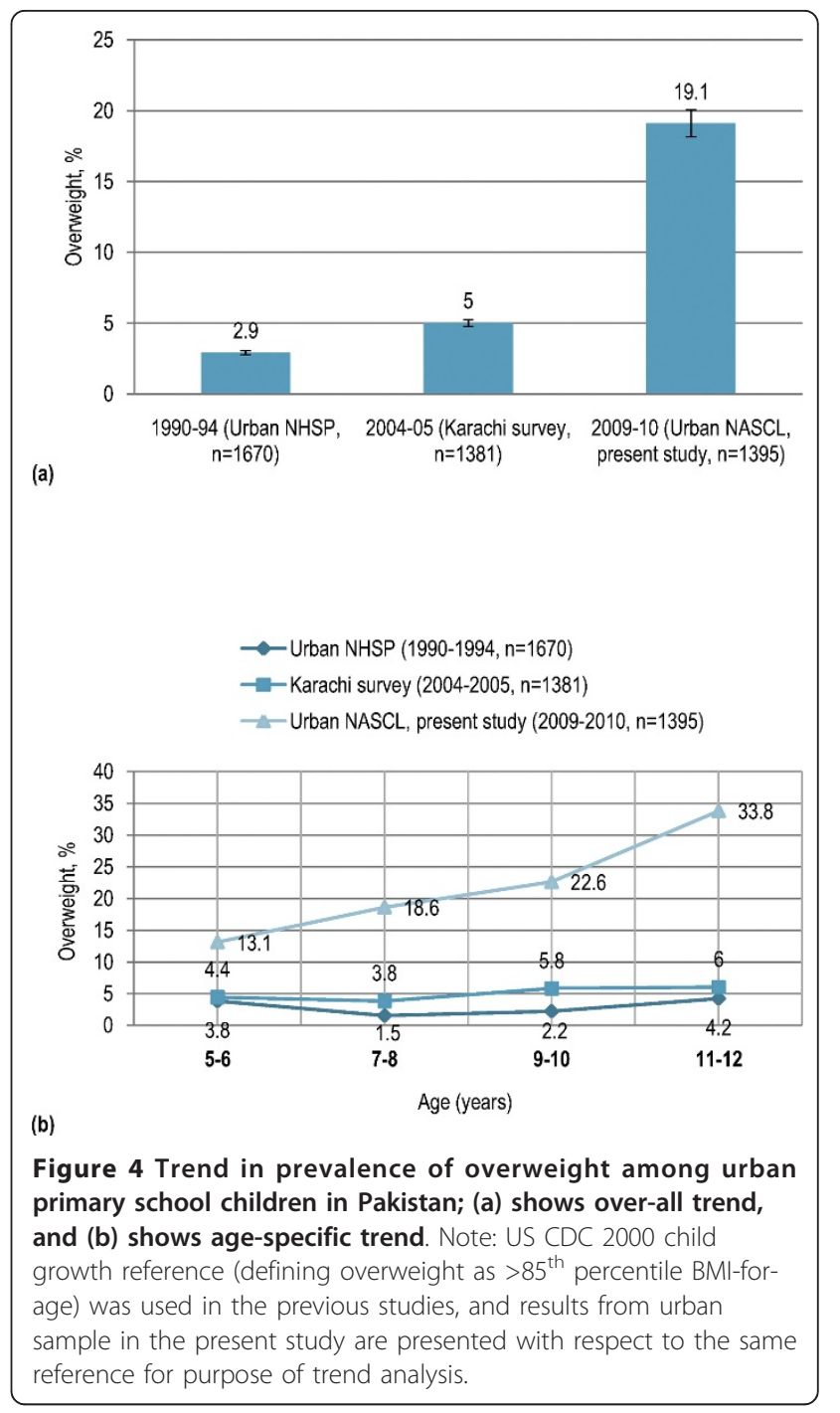

Table 5 Logistic regression model of factors associated with overweight (including obesity) among primary school children in Lahore, Pakistan $(n=1860)^{a}$

\begin{tabular}{|c|c|c|c|c|}
\hline \multirow[b]{2}{*}{ Characteristics } & \multicolumn{4}{|c|}{ Over-weight, including obese $(n=316)$} \\
\hline & Crude OR (95\% Cl) & P Value & Adjusted OR (95\% Cl) ${ }^{a}$ & P Value \\
\hline \multicolumn{5}{|l|}{ Grade } \\
\hline One & Reference & - & Reference & - \\
\hline Two & $0.75(0.48-1.15)$ & 0.187 & $0.80(0.49-1.32)$ & 0.379 \\
\hline Three & $1.23(0.83-1.83)$ & 0.313 & $1.52(0.85-2.72)$ & 0.159 \\
\hline Four & $1.70(1.16-2.49)$ & 0.006 & $2.39(1.17-4.90)$ & 0.017 \\
\hline Five & $1.55(1.05-2.27)$ & 0.027 & $2.28(0.98-5.31)$ & 0.057 \\
\hline \multicolumn{5}{|c|}{ Area and socioeconomic status (SES) } \\
\hline Urban, high SES & $17.55(9.98-30.88)$ & $<0.001$ & $18.10(10.24-32.00)$ & $<0.001$ \\
\hline Urban, middle SES & $8.94(5.03-15.90)$ & $<0.001$ & $8.52(4.65-15.60)$ & $<0.001$ \\
\hline Urban, low SES & $2.70(1.44-5.08)$ & 0.002 & $2.55(1.29-5.02)$ & 0.007 \\
\hline Rural, low/disadvantaged SES & Reference & - & Reference & - \\
\hline
\end{tabular}

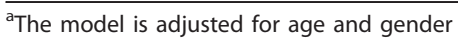


States [33-37]. Grade- and gender- specific prevalence trend showed that more boys were overweight in grades one and two while more girls were overweight in grades three to five. Moreover, the mean BMI was higher in boys in grades one and two as compared to girls while in grades four and five a higher BMI in girls was observed. Higher prevalence among girls in higher grades may be due to genetic factors and pubertal growth spurt. More boys were overweight in the urban area with high SES where highest obesity prevalence was observed. A possible explanation for higher body fatness among boys might be the socio-cultural matrix in South Asia where parents prioritize boys, especially in the younger age groups, in feeding practices. Parents are less likely to encourage sons to lose weight, perhaps because of the larger and more muscular ideal male body shape [38]. Prevalence of overweight showed a significantly increasing trend with grade and age and higher grade independently predicted the risk of being overweight. The findings are consistent with previous studies in Pakistan and elsewhere [21,23,39,40].

Living in the urban area with higher SES was strong independent predictor of being at risk for overweight. Higher obesity prevalence was reported in the Pakistani adults living in urban areas and having high SES [40]. Increased prevalence of overweight with urbanization have been reported both in the developing and developed countries [21,29,41,42]. Higher prevalence of overweight with high SES was observed in the present study, in contradiction to higher prevalence of overweight with low SES observed previously in the developed countries like United States and developing countries like Brazil $[34,41,43]$. Different socio-cultural circumstances in South Asia explain the contradiction and studies in India have indicated the same trend with prevalence increasing with higher SES $[44,45]$. In the developing countries, gross national product (GNP) has been associated positively with overweight among pre-school children [46]. Prevalence of overweight was higher in private schools than public schools, consistent with a study in Brazil [47].

Urbanized lifestyle including reduced physical activity and increased sedentary living and unhealthy diets high in saturated fats, sugar and refined foods are the probable causes of the emerging childhood obesity epidemic in the developing countries undergoing nutrition transition $[29,32,48]$. Increasingly obesogenic environments reinforced by many of the cultural changes associated with globalization further aggravate the situation, especially among children and adolescents [32]. Efforts to stop childhood obesity should be made on all fronts and targeted interventions, tailored to local circumstances and involving communities, should begin early in life $[13,14,20]$.
Prevention and treatment efforts, following a global approach with proper monitoring and implementation, are effective and there is little evidence of negative effects, either physiological or psychological $[22,49,50]$. Suggested approaches include labeled diets, exercise sessions and increased general lifestyle activity combined with the use of behavioral change methods [50]. Familybased interventions are routinely recommended for obese school-aged children and school-based programs are recommended for those at risk of being overweight and obese [49]. Rapidly increasing rates of obesity among school-aged children in Pakistan suggest the urgent need for a primary prevention program [51]. A National preventive strategy for childhood obesity should be developed and a pilot preventive program should be initiated. Currently, School Health and Nutrition Supervisors working in Pakistan's National Maternal, Newborn, and Child Health (MNCH) Program can be used for growth monitoring and BMI tracking in school-going children.

Cross-sectional nature of the study should be considered when interpreting the findings. Future longitudinal studies involving these factors are therefore warranted to establish the temporal nature and causality of these associations. Although data collection followed a standard protocol, digital scales were not used. Variability in the data ascertainment may have introduced error into the prevalence estimates; however, we do not anticipate large or systematic differences. The findings can be generalized to South Asian primary school children, who share the same genetic and environmental factors with the sample. We speculate that overweight may be a greater issue in a greater number of countries among school-aged children and countries contemplating nutrition surveys ought to consider including school-aged children.

\section{Conclusion}

Alarmingly rapid rise in overweight and obesity among Pakistani primary school children was observed, especially among the affluent urban population. The findings support the urgent need for National preventive strategy for childhood obesity and targeted interventions tailored to local circumstances with meaningful involvement of communities.

\section{Acknowledgements}

We dedicate the work to loving memories of Ubeera Shahid (1987-2010, Allama Iqbal Medical College Class of 2011) who left us in an unfortunate motorway car accident. We are grateful to Professor Arif M Siddiqui, MBBS, MRCP, FRCP (Eng), FRCP (Ed), FRCP (Glasg), Usman Khurshid, MBBS, Komal Mushtaq, Fourth year MBBS and others at the Ubeera Memorial Research Society of Allama labal Medical College, Lahore, Pakistan. We would like to thank Dina H Kakar, MD, Andrea Lyman, MD, MSc, MS and Douglas C Proops MD, MPH. We are indebted to the Punjab Departments 
of Health and Education and the children, parents and staff at sampled schools. We acknowledge partial financial support from Allama lqbal Medical College, Lahore, Pakistan.

\section{Author details}

'Ubeera Memorial Research Society, Allama Iqbal Medical College, Lahore, 54000 Punjab, Pakistan. ${ }^{2}$ District Health Office Nankana Sahib, Punjab Department of Health, Nankana Sahib, 39100 Punjab, Pakistan. ${ }^{3}$ King Edward Medical University, Lahore, 54000 Punjab, Pakistan.

\section{Authors' contributions}

All authors contributed significantly in all phases of the study in accordance with uniform requirements established by the International Committee of Medical Journal Editors. All authors read and approved the final manuscript.

\section{Competing interests}

The authors declare that they have no competing interests.

Received: 8 June 2011 Accepted: 25 September 2011 Published: 25 September 2011

\section{References}

1. World Health Organization, Global Strategy on Diet, Physical Activity and Health: Overweight and obesity.[http://www.who.int/dietphysicalactivity/ en/index.html]

2. World Health Organization: Global Strategy on Diet, Physical Activity and Health Geneva; 2004.

3. Prentice AM: The emerging epidemic of obesity in developing countries. Int J Epidemiol 2006, 35:93-99.

4. Lobstein T, Baur L, Uauy R: Obesity in children and young people: a crisis in public health. Obes Rev 2004, 5(Suppl 1):4-104

5. Dietz WH, Robinson TN: Overweight children and adolescents. N Engl J Med 2005, 352:2100-2109.

6. Must A, Strauss RS: Risks and consequences of childhood and adolescent obesity. Int J Obes Relat Metab Disord 1999, 23(Suppl 2):S2-11.

7. Viner RM, Cole TJ: Adult socioeconomic, educational, social, and psychological outcomes of childhood obesity: a national birth cohort study. BMJ 2005, 330(7504):1354.

8. Dietz WH: Health consequences of overweight in youth: childhood predictors of adult disease. Pediatrics 1998, 101(3):518-525.

9. Must A, Spadano J, Coakley EH, Field AE, Colditz G, Dietz WH: The disease burden associated with overweight and obesity. JAMA 1999, 282:1523-1529

10. World Health Organization (WHO): Obesity: Preventing and Managing the Global Epidemic Geneva; 2000, (WHO technical report series 894).

11. Han JC, Lawlor DA, Kimm SYS: Childhood obesity. Lancet 2010, 375:1737-1748.

12. Popkin BM, Doak CM: The obesity epidemic is a worldwide phenomenon Nutrition Reviews 1998, 56:106-114.

13. Baltrus PT, Lynch JW, Everson-Rose S, Raghunathan TE, Kaplan GA: Race/ Ethnicity, Life-Course Socioeconomic Position, and Body Weight Trajectories Over 34 years: The Alameda County Study. Am J Public Health 2005, 95(9):1595-1601.

14. Reilly JJ: Tackling the obesity epidemic: new approaches. Arch Dis Child 2006 91:724-726.

15. Thorpe LE, List DG, Marx T, May L, Helgerson SD, Frieden TR: Childhood obesity in New York City elementary school students. Am J Public Health 2004, 94(9):1496-1500

16. Wolfe WS, Campbell CC, Frongillo EA Jr, Haas JD, Melnik TA: Overweight schoolchildren in New York State: prevalence and characteristics. Am J Public Health 1994, 84(5):807-813, Erratum in: Am J Public Health 2005, 95 (7):1093.

17. Veugelers PJ, Fitzgerald AL: Prevalence of and risk factors for childhood overweight and obesity. CMAJ 2005, 173(6):607-613.

18. Kelishadi R, Ardalan G, Gheiratmand R, et al: Association of physical activity and dietary behaviours in relation to the body mass index in a national sample of Iranian children and adolescents: CASPIAN Study. Bull World Health Organ 2007, 85:19-26.

19. Whelton $\mathrm{H}$, Harrington J, Crowley E, Kelleher V, Cronin M, Perry IJ: Prevalence of overweight and obesity on the island of Ireland: results from the North South Survey of Children's Height, Weight and Body Mass Index, 2002. BMC Public Health 2007, 7:187.

20. Will B, Zeeb H, Baune BT: Overweight and obesity at school entry among migrant and German children: a cross-sectional study. BMC Public Health $2005,5: 45$

21. Apfelbacher CJ, Loerbroks A, Cairns J, Behrendt H, Ring J, Kramer U: Predictors of overweight and obesity in five to seven-year-old children in Germany: Results from cross-sectional studies. BMC Public Health 2008, $8: 171$

22. Summerbell CD, Waters E, Edmunds LD, Kelly S, Brown T, Campbell KJ Interventions for preventing obesity in children. Cochrane Database of Systematic Reviews 2005, , 3: CD001871.

23. Jafar TH, Qadri Z, Islam M, Hatcher J, Bhutta ZA, Chaturvedi N: Rise in childhood obesity with persistently high rates of undernutrition among urban school-aged Indo-Asian children. Arch Dis Child 2008, 93(5):373-378.

24. Sweeting $\mathrm{H}$ : Measurement and definitions of obesity in childhood and adolescence: a field guide for the uninitiated. Nutr J 2007, 6:32.

25. East High Scales China Scale Manufacturer Nanjing China: ZT Mechanical Physician Scale.[http://www.easthighscale.com/ZT-Mechanical-PhysicianScale.html].

26. World Health Organization: WHO Child Growth Standards.[http://www who.int/growthref/en/]

27. Butte NF, Garza C, de Onis M: Evaluation of the feasibility of international growth standards for school-aged children and adolescents. J Nutr 2007, 137:153-157.

28. Cole TJ, Bellizzi MC, Flegal KM, Dietz WH: Establishing a standard definition for child overweight and obesity worldwide: international survey. BMJ 2000, 320:1240-1243

29. Wang $Y$, Lobstein $\mathrm{T}$ : Worldwide trends in childhood overweight and obesity. Int J Pediatr Obes 2006, 1:11-25.

30. Ogden $C L$, Carroll MD, Curtin LR, et al: Prevalence of overweight and obesity in the United States, 1999-2004. JAMA 2006, 295(13):1549-1555.

31. Stein $A D$, Thompson AM, Waters $A$ : Childhood growth and chronic disease: evidence from countries undergoing the nutrition transition. Matern Child Nutr 2005, 1:177-184

32. Chopra M, Galbraith S, Darnton-Hill I: A global response to a global problem: the epidemic of overnutrition. Bull World Health Organ 2002, 80:952-958.

33. Ramachandran A, Snehalatha C, Vinitha R, et al: Prevalence of overweight in urban Indian adolescent school children. Diabetes Res Clin Pract 2002, 57:185-190.

34. da Veiga GV, da Cunha AS, Sichieri R: Trends in overweight among adolescents living in the poorest and richest regions of Brazil. Am J Public Health 2004, 94(9):1544-1548.

35. Kautiainen S, Rimpela A, Vikat A, Virtanen SM: Secular trends in overweight and obesity among Finnish adolescents in 1977-1999. Int J Obes 2002, 26:544-552.

36. Tremblay MS, Katzmarzyk PT, Willms JD: Temporal trends in overweight and obesity in Canada, 1981-1996. Int J Obes 2002, 26:538-543.

37. New York City Department of Health and Mental Hygiene: Youth Risk Behavior Survey.[http://www.nyc.gov/html/doh/html/episrv/episrvyouthriskbehavior.shtml].

38. Ricciardelli LA, McCabe MP: Children's body image concerns and eating disturbance: A review of the literature. Clin Psychol Rev 2001, 21(3):325-344

39. Kinra S, Nelder RP, Lewendon GJ: Deprivation and childhood obesity: cross sectional study of 20973 children in Plymouth, United Kingdom. J Epidemiol Community Health 2000, 54:456-460.

40. Ahmad K, Jafar TH, Chaturvedi N: Self-rated health in Pakistan: results of a national health survey. BMC Public Health 2005, 5:51

41. Wang Y, Beydoun MA: The Obesity Epidemic in the United StatesGender, Age, Socioeconomic, Racial/Ethnic, and Geographic Characteristics: A Systematic Review and Meta-Regression Analysis. Epidemiol Rev 2007, 29:6-28.

42. Mamalakis G, Kafatos A, Manios Y, Anagnostopoulou A, Apostolaki I: Obesity indices in a cohort of primary school children in Crete: a six year prospective study. Int J Obes 2000, 24:765-771.

43. Monteiro CA, Conde WL, Popkin BM: The burden of disease from undernutrition and overnutrition in countries undergoing rapid nutrition transition: a view from Brazil. Am J Public Health 2004, 94:433-434. 
44. Sidhu S, Marwah G, Prabhjot : Prevalence of overweight and obesity among the affluent adolescent school children of Amritsar Punjab. Coll Antropol 2005, 29:53-55.

45. Chhatwal J, Verma M, Riar SK: Obesity among pre-adolescent and adolescents of a developing country (India). Asia Pac J Clin Nutr 2004, 13:231-235.

46. Martorell R, Khan LK, Hughes ML, Grummer-Strawn LM: Overweight and obesity in preschool children from developing countries. Int J Obes 2000, 24:959-967.

47. Oliveira AM, Oliveira AC, Almeida MS, Oliveira N, Adan L: Influence of the family nucleus on obesity in children from northeastern Brazil: a crosssectional study. BMC Public Health 2007, 7:235.

48. Popkin BM: An overview on the nutrition transition and its health implications: the Bellagio meeting. Public Health Nutr 2002, 5:93-103.

49. American Dietetic Association, Ritchie LD, Crawford PB, Hoelscher D, Sothern MS: Position of the American Dietetic Association: individual-, family-, school-, and community-based interventions for pediatric overweight. J Am Diet Assoc 2006, 106:925-945.

50. Epstein LH, Myers MD, Raynor H, Saelens BE: Treatment of pediatric obesity. Pediatrics 1998, 101(3):554-570.

51. Misra A, Vikram NK, Sharma R, Basit A: High prevalence of obesity and associated risk factors in urban children in India and Pakistan highlights immediate need to initiate primary prevention program for diabetes and coronary heart disease in schools. Diabetes Res Clin Pract 2006, 71:101-102.

\section{Pre-publication history}

The pre-publication history for this paper can be accessed here: http://www.biomedcentral.com/1471-2458/11/724/prepub

doi:10.1186/1471-2458-11-724

Cite this article as: Mushtaq et al: Prevalence and socioeconomic correlates of overweight and obesity among Pakistani primary school children. BMC Public Health 2011 11:724.

\section{Submit your next manuscript to BioMed Central and take full advantage of:}

- Convenient online submission

- Thorough peer review

- No space constraints or color figure charges

- Immediate publication on acceptance

- Inclusion in PubMed, CAS, Scopus and Google Scholar

- Research which is freely available for redistribution

Submit your manuscript at www.biomedcentral.com/submit 